\title{
Severe hypophosphataemic osteomalacia related to low-dose adefovir dipivoxil therapy in a hepatitis $B$ virus patient
}

\author{
Xiushuai Dong, Xi Chen, Yaoyao Tian, Jinghua Wang \\ Department of Haematology, The Second Affiliated Hospital, Harbin Medical University, Harbin, China
}

Key words: hypophosphataemic osteomalacia; adefovir dipivoxil; chronic hepatitis B

A 47-year-old man presented in September 2011 with a 2-year history of bone pain without antecedent trauma. He began to complain of mild pain in the lumbosacral region and did not pay attention to it in August 2009. However, he reported generalised bone pain involving the sternum, several ribs, left ankle, and large joints, and progressive weakness in his muscles, especially in his leg muscles, in May 2011. A diagnosis of ankylosing spondylitis was made in some hospitals. Although given conventional therapy, including nonsteroidal anti-inflammatory drugs, sulfasalazine, methotrexate, and the supplementation of calcium and vitamin $D$, the patient did not show considerable improvement in bone pain. He was laid up due to long illness.

The patient's past medical history was uncomplicated. He had a history of chronic hepatitis B infection and cirrhosis, receiving adefovir dipivoxil at $10 \mathrm{mg}$ daily for 49 months. He was without hypertension or diabetes mellitus and previously had not taken any other medication known to harm the skeletal system. On physical examination, he presented severe tenderness over the sternum, the ribs, both shoulder joint areas, sacroiliac joint, knee joint, and left ankle. The remainder of the clinical examination was approximately normal.

Laboratory examination on admission revealed severe hypophosphataemia $(0.42 \mathrm{mmol} / \mathrm{L})$, mild hypocalcaemia $(2.05 \mathrm{mmol} / \mathrm{L})$, and an increased serum creatinine (131 umol/L). Alkaline phosphatase was elevated (245 $\mathrm{U} / \mathrm{L})$, but parathyroid hormone and vitamin D were within normal range. ALT and AST were $17 \mathrm{IU} / \mathrm{L}$ and $19 \mathrm{IU} / \mathrm{L}$, respectively. However, in his serum hepatitis B virus (HBV) DNA was detected $(1.354 \mathrm{e}+003$ copies $/ \mathrm{mL}$; normal range, $\leq 5.000 \mathrm{e}+002$ copies $/ \mathrm{mL}$ ). A routine blood test demonstrated a decreased haemoglobin level (98 $\mathrm{g} / \mathrm{L}$ ) and normal leukocyte and platelet count. Bone marrow biopsy was performed, and nothing abnormal was found. Vitamin B12, folate, and haemolytic test were normal, and iron was slightly elevated. Urinalysis indicated positive albumin and glucose. A 24-hour urinary study showed hyperphosphaturia. Ultrasound examination showed a diffused hepatic and renal lesion. No splenomegaly was found. Dual-energy X-ray absorptiometry revealed a decreased hip joint bone mineral density of $0.724 \mathrm{~g} / \mathrm{cm}^{2}$ (T-score, -1.7; Z-score, -1.2). A whole-body ${ }^{99 \mathrm{~m}} \mathrm{Tc}-\mathrm{methylene}$ diphosphonate ( $\left.{ }^{99 \mathrm{~m}} \mathrm{Tc}-\mathrm{MDP}\right)$ bone scan showed widespread foci in the ribs bilaterally, both shoulder joints, the sacroiliac joints, the right femoral head, the knees, and the left ankle (Fig. 1). The patient refused the recommendation of kidney biopsy.

A diagnosis of hypophosphataemic osteomalacia secondary to low-dose adefovir dipivoxil therapy was made. Entecavir $0.5 \mathrm{mg}$ daily was given to replace adefovir dipivoxil. Both laboratory parameters and bony pain improved dramatically after oral phosphate and

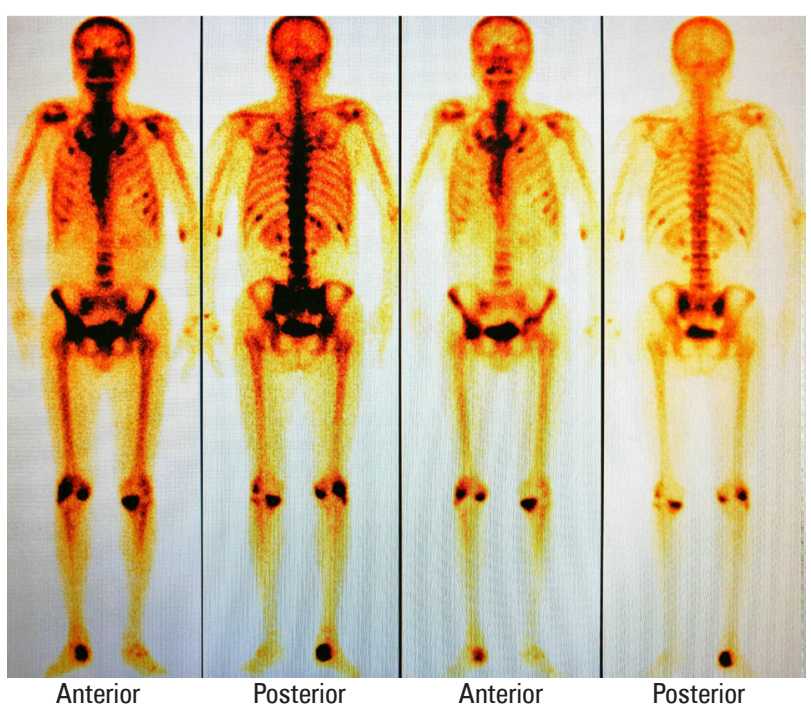

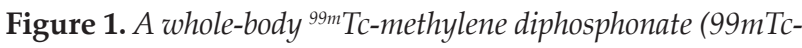
$-M D P)$ bone scan shows multiple foci of increased radiotracer uptake in the ribs bilaterally, both shoulder joints, the sacroiliac joints, the right femoral head, the knees, and the left ankle 
Table 1. Laboratory data

\begin{tabular}{lcccc}
\hline Laboratory test & 2 months earlier & At admission & $\mathbf{8}$ weeks after ADV withdrawal & Reference range \\
\hline Serum & & & & $(4-10) \times 109 / \mathrm{L}$ \\
\hline White blood cells & 4.2 & 7.7 & 8.5 & $(110-160) \mathrm{g} / \mathrm{L}$ \\
\hline Haemoglobin & 87 & 98 & 126 & $(100-300) \times 109 / \mathrm{L}$ \\
\hline Platelets & 150 & 203 & 287 & $(0-40) \mathrm{U} / \mathrm{L}$ \\
\hline ALT & 22 & 17 & 17 & $(0-40) \mathrm{U} / \mathrm{L}$ \\
\hline AST & 24 & 17 & 19 & $(35-150) \mathrm{U} / \mathrm{L}$ \\
\hline Alkaline phosphatase & 154 & 241 & 175 & $(35-55) \mathrm{g} / \mathrm{L}$ \\
\hline Albumin & 36.6 & 36.5 & 40.1 & $(2.3-7.2) \mathrm{umol} / \mathrm{L}$ \\
\hline Blood urea nitrogen & 4.61 & 4.17 & 3.78 & $(44-110) \mathrm{umol} / \mathrm{L}$ \\
\hline Creatinine & 116 & 131 & 89 & $(3.9-6.1) \mathrm{mmol} / \mathrm{L}$ \\
\hline Glucose & 4.84 & 4.15 & 4.79 & $(101-111) \mathrm{mmol} / \mathrm{L}$ \\
\hline Chloride & 115.5 & 108.7 & 109 & $(135-145) \mathrm{mmol} / \mathrm{L}$ \\
\hline Sodium & 144.7 & 142.6 & 139 & $(2.1-2.8) \mathrm{mmol} / \mathrm{L}$ \\
\hline Calcium & 1.94 & 2.05 & 2.37 & $(0.8-1.4) \mathrm{mmol} / \mathrm{L}$ \\
\hline Phosphate & 0.26 & 0.92 & $(3.5-5.5) \mathrm{mmo} / \mathrm{L}$ \\
\hline Potassium & 2.88 & 3.87 & 4.03 & $(6.0-80) \mathrm{pg} / \mathrm{mL}$ \\
\hline Parathyroid hormone & NA & 26.97 & $\mathrm{NA}$ & $(26-65) \mathrm{ng} / \mathrm{L}$ \\
\hline 1,25-(OH)2 vitamin D3 & NA & 31.58 & $\mathrm{NA}$ & \\
\hline
\end{tabular}

ADV — adefovir dipivoxil; NA — not available; ALT — alanine aminotransferase; AST — aspartate transaminase

vitamin D supplementation (Tab. 1). One month after cessation of adefovir dipivoxil, bony pain involving the ribs and the sacroiliac joints disappeared. After 7 weeks, the patient could walk without restraint. So far, he has been given a follow-up for 9 years, and reported no bone pain. Serum creatinine, phosphorus, and liver function are normal, and virus replication is at a low level.

Adefovir dipivoxil, an oral nucleotide analogue, has been widely used for the treatment of hepatitis B. It does not produce significant hepatotoxicity, due to minimal hepatic metabolism. However, it displays a dose-dependent nephrotoxicity [1]. Adefovir dipivoxil at a daily dose of $30 \mathrm{mg}$ can cause a mild-to-moderate degree of nephrotoxicity, while no evidence of renal dysfunction was seen at a dose of $10 \mathrm{mg}$ per day after follow-up for 16 months in 2 randomised controlled trials [2]. However, subsequent reports have indicated a high prevalence of nephrotoxicity associated with prolonged usage of adefovir dipivoxil at a lower dose. The excessive accumulation of adefovir dipivoxil in the proximal renal tubules inhibits mitochondrial DNA replication, and can lead to the disorders in phosphorus homeostasis, but it can also disturb reabsorption of protein, glucose, uric acid, and other ions (Fanconi syndrome). Sustained loss of phosphate disturbs normal bone mineralisation and eventually results in osteomalacia [3]. After the cessation of adefovir dipivoxil, nephrotoxicity is partly reversible in some patients [4].

Herein, we report a typical case of hypophosphataemic osteomalacia in a hepatitis B patient following treatment with low-dose adefovir dipivoxil for 49 months. Clinicians should be aware of serious adverse reactions during the use of adefovir dipivoxil at the lower dose of $10 \mathrm{mg}$ daily. Liver function, renal function, and serum electrolytes should be tested closely so as to recognise this complication of drugs and provide appropriate intervention as soon as possible. At the same time, it is important to distinguish hypophosphataemic osteomalacia from ankylosing spondylitis and multiple myeloma. The correct diagnosis can reduce patients' pain and improve their quality of life.

\section{Authors' contribution}

Xiushuai Dong drafted the manuscript. Xi Chen, Yaoyao Tian, and Jinghua Wang critically revised the manuscript. All authors contributed to the intellectual content and approved the final version.

\section{Funding}

None.

\section{Conflict of interest}

All the authors declare no conflict of interest.

\section{References}

1. Leowattana W. Antiviral Drugs and Acute Kidney Injury (AKI). Infect Disord Drug Targets. 2019; 19(4): 375-382, doi: 10.2174/18715265196661 90617154137, indexed in Pubmed: 31288730.

2. Izzedine H, Hulot JS, Launay-Vacher V, et al. Adefovir Dipivoxil International 437 Study Group, Adefovir Dipivoxil International 438 Study Group. Renal safety of adefovir dipivoxil in patients with chronic hepatitis B: two double-blind, randomized, placebo-controlled studies. Kidney Int. 2004; 66(3): 1153-1158, doi: 10.1111/j.1523-1755.2004.00 866.x, indexed in Pubmed: 15327411.

3. Park S, Kim WI, Cho DH, et al. Adefovir-induced Fanconi syndrome associated with osteomalacia. Clin Mol Hepatol. 2017; 24(3): 339-344 doi: 10.3350/cmh.2017.0009, indexed in Pubmed: 28859264.

4. Lv Y, Li X, Liang S, et al. The clinical and pathological features of adefovir dipivoxil-related renal impairment . Clin Nephrol. 2019; 91(3): 180-186, doi: 10.5414/CN109574, indexed in Pubmed: 30614440. 